\title{
A role for the clock period circadian regulator 2 gene in regulating the clock gene network in human oral squamous cell carcinoma cells
}

\author{
YIRAN AO $^{1}$, QIN ZHAO $^{1}$, KAI YANG $^{*}$, GANG ZHENG $^{2 *}$, XIAOQING LV $^{1}$ and XIAOLI SU ${ }^{1}$ \\ ${ }^{1}$ Department of Oral and Maxillofacial Surgery, The First Affiliated Hospital of Chongqing Medical University, \\ Chongqing 400016; ${ }^{2}$ Anorectal Department, Chongqing Traditional Chinese Medicine Hospital, Chongqing 400021, P.R. China
}

Received August 4, 2016; Accepted November 29, 2017

DOI: $10.3892 / 01.2018 .7825$

\begin{abstract}
Clock genes are the core of the circadian rhythms in the human body and are important in regulating normal physiological functions. To date, research has indicated that the clock gene, period circadian clock 2 (PER2), is downregulated in numerous types of cancer, and that it is associated with cancer occurrence and progression via the regulation of various downstream cell cycle genes. However, it remains unclear whether the decreased expression of PER2 influences the expression of other clock genes in cancer cells. In the present study, short hairpin RNA interference was used to knockdown PER2 effectively in human oral squamous cell carcinoma SCC15 cells. Quantitative polymerase chain reaction was used to assess the mRNA expression levels of various clock genes and revealed that, following the knockdown of PER2 in SCC15 cells, the mRNA expression levels of $P E R 3$, brain and muscle ARNT-like 1, deleted in esophageal cancer $(D E C) 1, D E C 2$, cryptochrome circadian clock $(C R Y) 2$, timeless circadian clock, retinoic acid receptor-related orphan receptor-alpha and neuronal PAS domain protein 2 were significantly downregulated, while the mRNA expression levels of PER 1 and nuclear receptor subfamily 1 group D member 1 were significantly upregulated. In addition, flow cytometric analysis demonstrated that proliferation was enhanced and
\end{abstract}

Correspondence to: Professor Kai Yang, Department of Oral and Maxillofacial Surgery, The First Affiliated Hospital of Chongqing Medical University, 1 Youyi Road, Yuzhong, Chongqing 400016, P.R. China

E-mail: cqfyyk@hotmail.com

*Contributed equally

Abbreviations: CCGs, clock-controlled genes; shRNA, short hairpin RNA; OSCC, oral squamous cell carcinoma; RT-qPCR, reverse transcription-quantitative polymerase chain reaction; PVDF, polyvinylidene fluoride; ECL, enhanced chemiluminescence

Key words: clock genes, period circadian clock 2, tumor, oral cancer, RNA, gene expression apoptosis was reduced following PER2 knockdown in SCC15 cells $(\mathrm{P}<0.05)$. To the best of our knowledge, the present study is the first to report that $P E R 2$ is important for the regulation of other clock genes of the clock gene network in cancer cells. This is of great significance in elucidating the molecular function and tumor suppression mechanism of PER2.

\section{Introduction}

The human body possesses a circadian clock, which serves an important role in regulating normal physiological functions (1). Clock genes are at the core of this circadian clock. To date, 14 clock genes have been identified: Clock circadian regulator (CLOCK), brain and muscle ARNT-like 1 (BMAL1), period circadian clock $(P E R) 1, P E R 2, P E R 3$, deleted in esophageal cancer $(D E C) 1, D E C 2$, cryptochrome circadian clock $(C R Y) 1$, $C R Y 2$, timeless circadian clock (TIM), casein kinase 1 epsilon $(C K I \varepsilon)$, retinoic acid receptor-related orphan receptor- $\alpha$ $(R O R \alpha)$, neuronal PAS domain protein 2 (NPAS2) and nuclear receptor subfamily 1 group $\mathrm{D}$ member $1(R E V-E R B \alpha)(2-5)$, all of which exist in the majority of human cells (6). In mammals, $2-10 \%$ of the genome is regulated by these clock genes $(7,8)$, including numerous key cell cycle genes and cancer-associated genes (9-11); these are termed clock-controlled genes (CCGs). Different clock genes regulate different downstream CCGs and, thus, clock genes are important in regulating cell biochemical and physiological functions (12).

$P E R 2$ is an important clock gene, and previous research has indicated that PER2 serves a notable function in the occurrence and progression of cancer $(13,14)$. The expression of PER2 has been revealed to be downregulated in various types of cancer, including breast cancer, gastric carcinoma, head and neck cancer and oral cancer (15-18). PER2 regulates a number of downstream cell cycle genes and cancer-associated genes, including cyclin D1, cyclin A, tumor protein p53, v-Myc avian myelocytomatosis viral oncogene homolog, mouse double minute 2 homolog proto-oncogene and B-cell lymphoma 2 apoptosis regulator $(18,19)$. However, it remains unclear whether the decreased expression of PER2 in cancer cells is able to affect the expression of other clock genes.

The present study used short hairpin RNA (shRNA) interference to knockdown PER2 in human oral squamous cell 
carcinoma (OSCC) SCC15 cells, and reverse transcriptionquantitative polymerase chain reaction (RT-qPCR) was used to assess the altered mRNA expression of other clock genes. The mRNA expression levels of many clock genes, proliferation and apoptosis of tumor cells were altered. This research demonstrates that the effect of PER2 on tumor occurrence and progression is induced not only through the regulation of downstream CCGs, but also through the regulation of other clock genes in the network. This is of great significance to further illustrating the molecular functions and tumor-suppressive mechanisms of PER2.

\section{Materials and methods}

Construction of lentiviral shRNA plasmids. The mRNA sequence of $h P E R 2$ was acquired from the GenBank Database (http://www.ncbi.nlm.nih.gov/genbank/; accession no. NM_022817). BLAST screening (http://blast. ncbi.nlm.nih.gov/Blast.cgi) was used to ascertain three interference target sequences of PER2 (20): PER2-I, CAG AGTCCAGATACCTTTA; PER2-II, ATCCATATTTCA CTGTAAA; and PER2-III, CACACACAAAGAACTGAT A. Based on the design principles of Chernolovskaya and Zenkova (21), three RNA interference target sequences of PER2 were designed and synthesized: PER2-shRNA-I, PER2-shRNA-II and PER2-shRNA-III (Table I). The restriction enzymes AgeI/EcoRI (New England BioLabs, Inc., Ipswich, MA, USA) were used to double digest the lentiviral vector (Invitrogen; Thermo Fisher Scientific, Inc., Waltham, MA, USA), and the double enzyme-restricted vector was connected with PER2-shRNA-I-III, prior to the double-strand DNA being annealed using T4 DNA ligase in order to construct PER2-shRNA-I-III lentiviral plasmids. Scramble plasmids (Invitrogen; Thermo Fisher Scientific, Inc.), which exerted no interference effects on any genes, served as the controls (control-shRNA). Subsequently, these lentiviral plasmids were transformed into freshly prepared Escherichia coli DH5 $\alpha$ cells (Sangon Biotech Co., Ltd., Shanghai, China), selected in lysogeny broth medium containing the antibiotic ampicillin and then cultured overnight at $37^{\circ} \mathrm{C}$. Plasmids were extracted using a Qiagen Plasmid Midi kit (Qiagen GmbH, Hilden, Germany). qPCR was performed using a SYBR Premix Ex TaqII kit (Takara Bio, Inc., Otsu, Japan) in a reaction system comprising $5 \mu \mathrm{l}$ SYBR Premix Ex TaqII, $0.5 \mu \mathrm{l}$ each of the forward and reverse primer $(0.4 \mu \mathrm{mol} / \mathrm{l}$; Sangon Biotech Co., Ltd.), (forward primer sequence: 5'-CCATGATTCCTT CATATTTGC-3' and reverse primer sequence: 5'-GTAATA CGGTTATCCACGCG-3'), $2 \mu 1$ DNA template (50 ng/ $\mu$ l) and $2 \mu \mathrm{l}$ double distilled $\mathrm{H}_{2} \mathrm{O}\left(\mathrm{ddH}_{2} \mathrm{O}\right)$. The $\mathrm{dd}_{2} \mathrm{O}$ is the template for blank control, and the negative control was a template for an empty carrier that is not inserted in the target gene. The thermocycling conditions were as follows: Pre-denaturation at $95^{\circ} \mathrm{C}$ for $3 \mathrm{~min}$; denaturation for $30 \mathrm{sec}$ at $95^{\circ} \mathrm{C}$; annealing extension for $30 \mathrm{sec}$ at $55^{\circ} \mathrm{C}$ and $30 \mathrm{sec}$ at $72^{\circ} \mathrm{C}$, which for 22 cycles. Fluorescence signals were recorded during the $72^{\circ} \mathrm{C}$ annealing extension phase. The amplification products from PCR were assessed using a DNA sequencing assay (3730 DNA Analyzer; Applied Biosystems; Thermo Fisher Scientific, Inc.), and the results of DNA sequencing were analyzed using Chromas v2.4 software (Technelysium Pty Ltd., Brisbane, Australia).

Lentiviral PER2-shRNA plasmid packing. Each PER2shRNA-I-III and scramble plasmid $(8 \mu \mathrm{g})$ was mixed with $20 \mu 1$ Lipofectamine $^{\circledR} 2000$ (Invitrogen; Thermo Fisher Scientific, Inc.) and incubated for $15 \mathrm{~min}$ at room temperature. The mixture was then applied drop-wise to 293 cells (Institute of Life Sciences, Chongqing Medical University, Chongqing, China), which had been cultured to $70-80 \%$ growth density, and incubated in Dulbecco's modified Eagle's medium (DMEM; Thermo Fisher Scientific, Inc.) containing 10\% fetal bovine serum (FBS; Natocor Industria Biologica, Cordoba, Argentina) for $48 \mathrm{~h}$ at $37^{\circ} \mathrm{C}$ and $5 \% \mathrm{CO}_{2}$. Between 48 and $72 \mathrm{~h}$ after transfection, the culture supernatant was collected and centrifuged for $10 \mathrm{~min}$ at $4^{\circ} \mathrm{C}$ and $12,000 \mathrm{x}$ g to remove the cell debris, prior to being centrifuged again for $1 \mathrm{~h}$ at $4^{\circ} \mathrm{C}$ and 25,000 $\mathrm{x}$ g in overspeed centrifuge tubes. The sediment was then mixed with virus preservation solution and centrifuged for $5 \mathrm{~min}$ at $4^{\circ} \mathrm{Cand} 10,000 \mathrm{x} \mathrm{g}$. The supernatant was divided and four groups of lentiviral plasmids were obtained: PER2-shRNA-I, PER2-shRNA-II, PER2-shRNA-III and control-shRNA.

Cell transfection. SCC15 cells (Institute of Life Sciences, Chongqing Medical University) were cultured in Dulbecco's modified Eagle's medium/F-12 (Gibco; Thermo Fisher Scientific, Inc.) containing FBS and penicillin $100 \mathrm{U} / \mathrm{ml}$ and streptomycin $0.1 \mathrm{mg} / \mathrm{ml}$ (Yocon Biotechnology Co., Beijing, China) in cell culture flasks, at $37^{\circ} \mathrm{C}$ in an atmosphere containing $5 \% \mathrm{CO}_{2}$. Lentiviral plasmids $(5 \mu \mathrm{l})$ were applied drop-wise to SCC15 cells during the logarithmic growth phase, and $100 \mu 1$ Polybrene infection reagent (Sigma-Aldrich; Merck KGaA, Darmstadt, Germany) was added. Cells were incubated in DMEM containing 10\% FBS without antibiotics for $24 \mathrm{~h}$ $\left(37^{\circ} \mathrm{C}, 5 \% \mathrm{CO}_{2}\right)$, following which the medium was replaced every day with DMEM containing 10\% FBS and puromycin $(2 \mu \mathrm{g} / \mathrm{ml})$. Stably transfected SCC15 cells, in which PER2 was knocked down, were obtained following continuous cultivation for 7 days. The cells were divided into five experimental groups: PER2-shRNA-I, PER2-shRNA-II and PER2-shRNA-III groups (transfected with lentiviral plasmids PER2-shRNA-I to III, respectively); a control group (transfected with control-shRNA, expressing scramble shRNA); and an SCC15 group (untransfected SCC15 cells as a blank control).

Western blot analysis. Cells in the logarithmic growth phase were lysed at $4^{\circ} \mathrm{C}$ in radioimmunoprecipitation assay buffer (Beyotime Institute of Biotechnology, Haimen, China) for $30 \mathrm{~min}$ and collected by a cell scraper, following which the cell suspension was centrifuged for $5 \mathrm{~min}$ at $4^{\circ} \mathrm{C}$ and $12,000 \mathrm{xg}$ to collect the supernatant. Protein concentration was determined using a Bicinchoninic Acid Protein Assay kit (Beyotime Institute of Biotechnology), according to the manufacturer's protocols. Subsequently, the sample solution, containing $50 \mu \mathrm{g} / \mathrm{lane}$ protein, was subjected to SDS-PAGE (12\% gel). The proteins were transferred to polyvinylidene fluoride (PVDF) membranes (EMD Millipore, Billerica, MA, USA), which were subsequently blocked with 5\% dried skimmed milk for $1 \mathrm{~h}$ at room temperature. Following blocking, the membranes were 
Table I. Seque nces of PER2-shRNAs.

Group

Sense strand
Antisense strand
5'-AATTCAAAAAGCCAGAGTCCAGATACCTT TACTCGAGTAAAGGTATCTGGACTCTGGC-3' 5'-AATTCAAAAAGCATCCATATTTCACTGTAA ACTCGAGTTTACAGTGAAATATGGATGC-3' 5'-AATTCAAAAAGACACACACAAAGAACTG ATACTCGAGTATCAGTTCTTTGTGTGTGTC-3'

PER2, period circadian clock 2; shRNA, short hairpin RNA.

probed with a rabbit polyclonal anti-hPER2 antibody (1:300; ab180655; Abcam, Cambridge, UK) and a mouse monoclonal anti-hGAPDH antibody $(1: 1,000 ; 51332$; Cell Signaling Technology, Inc., Danvers, MA, USA) overnight at $4^{\circ} \mathrm{C}$, followed by three washes in PBS. Subsequently, the membranes were incubated with a horseradish peroxidase-conjugated goat anti-rabbit IgG antibody (Cell Signaling Technology, Inc.) for $2 \mathrm{~h}$ at room temperature, followed by three further washes in PBS. Under dark conditions, the enhanced chemiluminescent color-substrate solution (Beyotime Institute of Biotechnology) was applied to the PVDF membranes and exposed using chemiluminescence apparatus. A gel imaging system GelDoc 2000 (Bio-Rad Laboratories, Inc., Hercules, CA, USA) was used for visualization and protein detection. The ratio of the grey value of each PER2 band to that of GAPDH was calculated by ImageJ (version 1.48u; National Institutes of Health, Bethesda, MA, USA). All assays were performed in triplicate.

$R T-q P C R$. RT-qPCR was performed using the PrimeScript RT Reagent kit (cat no. RR037A; Takara Biotechnology Co., Ltd.) according to the manufacturers' protocols. Total RNA was extracted from cells using RNAiso Plus (Takara Biotechnology Co., Ltd.), prior to the RNA concentration and quality being determined using a UV/Visible spectrophotometer (GE Healthcare Life Sciences, Little Chalfont, UK) by measuring absorbance at 260 and $280 \mathrm{~nm}$. RNA was reverse transcribed to cDNA using a PrimeScript RT Reagent kit (Takara Biotechnology Co., Ltd.), according to the manufacturer's protocols. The reaction system comprised $5 \mathrm{X}$ Primer Script Buffer $(4 \mu 1)$, Primer Script RT Enzyme mix $(1 \mu 1)$, Oligo-dT Primers $(1 \mu \mathrm{l})$, Random Hexamers $(1 \mu \mathrm{l})$ and RNase Free $\mathrm{dH}_{2} \mathrm{O}(13 \mu \mathrm{l})$. The reverse transcription reaction conditions were $37^{\circ} \mathrm{C}$ for $15 \mathrm{~min}$ and $85^{\circ} \mathrm{C}$ for $5 \mathrm{sec}$. The qPCR primers for CLOCK, BMAL1, PER1, PER2, PER3, DEC1, DEC2, $C R Y 1, C R Y 2, T I M, C K I \varepsilon, R O R \alpha, N P A S 2$ and $R E V$-ERB $\alpha$ were designed using Oligo 7.0 primer analysis software (Molecular Biology Insights, Inc., Colorado Springs, CO, USA) and are listed in Table II. $\beta$-actin served as the normalization control. The reaction system comprised $5 \mu \mathrm{l}$ SYBR Premix Ex TaqII, $0.5 \mu \mathrm{l}$ each forward and reverse primer $(0.4 \mu \mathrm{mol} / \mathrm{l}), 2 \mu \mathrm{l}$ cDNA template $(50 \mathrm{ng} / \mu \mathrm{l})$ and $2 \mu \mathrm{l}$ double-distilled $\mathrm{H}_{2} \mathrm{O}$. The reaction conditions were as follows: Pre-denaturation at $95^{\circ} \mathrm{C}$ for $1.5 \mathrm{~min}$, followed by 40 cycles of denaturation for $10 \mathrm{sec}$ at $95^{\circ} \mathrm{C}$ and annealing extension for $30 \mathrm{sec}$ at $60^{\circ} \mathrm{C}$. Fluorescence signals were recorded during the $60^{\circ} \mathrm{C}$ annealing extension phase. The data were analyzed using the $2^{-\Delta \Delta \mathrm{Cq}}$ method (22). All assays were performed in triplicate.

Flow cytometry assay. To prepare a single-cell suspension, cells in the logarithmic growth phase were harvested by $0.25 \%$ trypsinization and centrifuged for $5 \mathrm{~min}$ at $800 \mathrm{x} \mathrm{g}$ and $4^{\circ} \mathrm{C}$, following which the supernatant was discarded, and the cell pellets were washed twice with pre-cooled PBS and were resuspended in PBS at a density of $1 \times 10^{6}$ cells $/ \mathrm{ml}$. The suspension was then divided into 1-ml aliquots in EP tubes. For the detection of cell cycle distribution and proliferation, 1-ml single-cell suspensions were centrifuged for $5 \mathrm{~min}$ at $800 \mathrm{x} \mathrm{g}$ and $4^{\circ} \mathrm{C}$ ) and the supernatants were discarded. Subsequently, $70 \%$ pre-cooled ethyl alcohol $\left(-20^{\circ} \mathrm{C}, 1 \mathrm{ml}\right)$ was added, mixed repeatedly and incubated overnight at $4^{\circ} \mathrm{C}$. The cells were resuspended in $1 \mathrm{ml} \mathrm{PBS}$, and $1 \mathrm{ml}$ RNase ribonuclease was added to the cell suspensions, followed by incubation for $40 \mathrm{~min}$ at $37^{\circ} \mathrm{C}$. Propidium iodide solution $(1 \mathrm{ml})$ was added and the mixture was kept in the dark for $10 \mathrm{~min}$ at $4^{\circ} \mathrm{C}$. Proliferation was analyzed using a FACS Vantage flow cytometer (BD Biosciences, Franklin Lakes, NJ, USA), and the ModFit LT 2.0 program (Verity Software House, Inc., Topsham, ME, USA) was used to analyze the proportion of cells in each phase of the cell cycle. The tumor cell proliferation index (PI) was calculated as follows: $\mathrm{PI}=[\mathrm{S}+(\mathrm{G} 2$ and $\mathrm{M})] /[(\mathrm{G} 0$ and $\mathrm{G} 1)+\mathrm{S}+(\mathrm{G} 2$ and $\mathrm{M})] \mathrm{x} 100$.

For the detection of cell apoptosis, the single-cell suspensions $(1 \mathrm{ml})$ were fixed in PBS for $2 \mathrm{~h}$ at $4^{\circ} \mathrm{C}$ and were then resuspended in Binding Buffer $(0.5 \mathrm{ml})$. The suspensions were incubated with Annexin V-FITC $(20 \mu \mathrm{g} / \mathrm{ml})$ reagent (Invitrogen; Thermo Fisher Scientific, Inc.) for 15 min at $4^{\circ} \mathrm{C}$ in the dark according to the manufacturer's protocols, and were then stained with $1 \mathrm{ml}$ propidium iodide solution for $2 \mathrm{~min}$ at room temperature in the dark. Apoptosis was analyzed using the FACS Vantage flow cytometer (BD FACS Aria II software; BD Biosciences, Franklin Lakes, NJ, USA). The tumor cell apoptotic index (AI) was calculated as follows: $\mathrm{AI}=$ (number of apoptotic cells/total number of cells) x100. Each experiment was performed in triplicate.

Statistical analysis. All statistical analyses were performed using SPSS 19.0 software (IBM Corp., Armonk, NY, USA). Comparisons between multiple groups were made using one-way analysis of variance, followed by the least significant difference test. Data are expressed as the mean \pm standard 


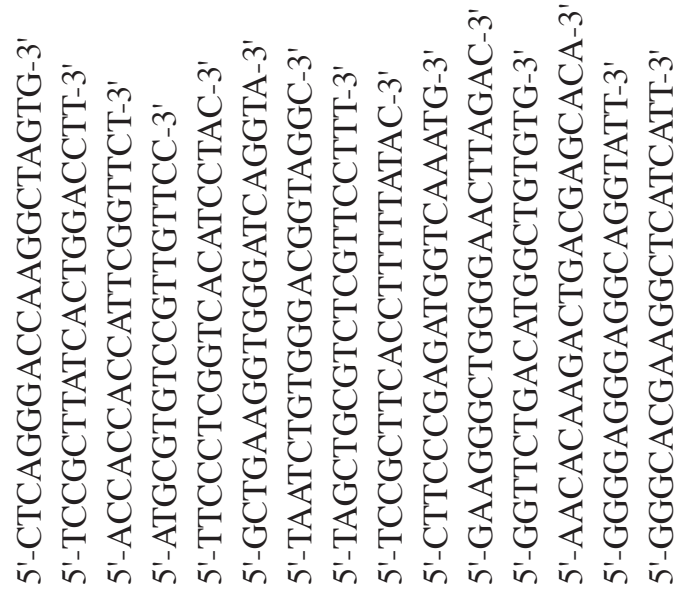

$\bar{m} \bar{m} \bar{m} \bar{m} \bar{m} \bar{m} \bar{m} \bar{c}$

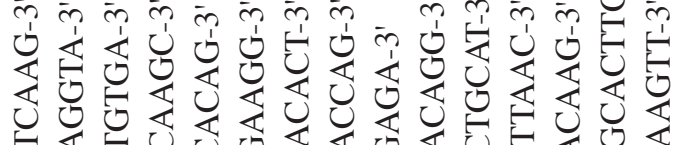

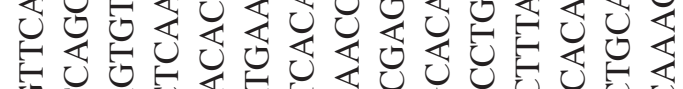

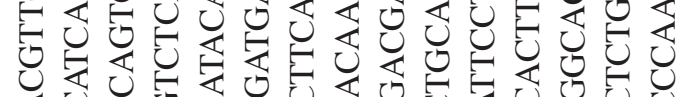

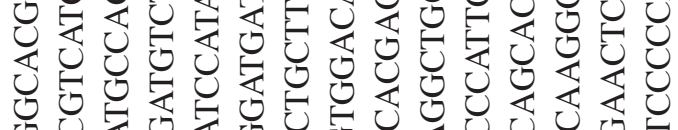

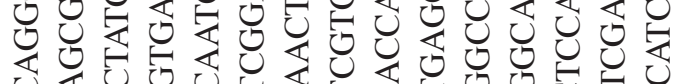

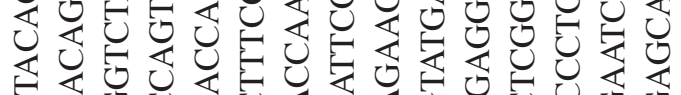

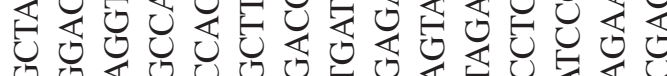

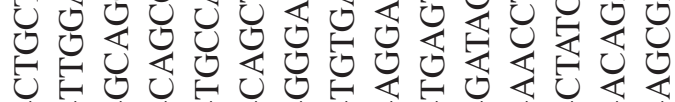

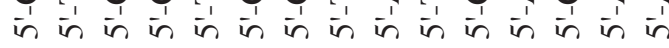


Table III. Sequences of PER2-shRNA interference.

\begin{tabular}{ll}
\hline Group & \multicolumn{2}{c}{ Sense strand } \\
\hline PER2-shRNA-I & 5'-CCGGGCCAGAGTCCAGATACCTTTACTCGAGTAAAGGTATCTGGACTCTGGCTTTTTG-3' \\
PER2-shRNA-II & 5'-CCGGGCATCCATATTTCACTGTAAACTCGAGTTTACAGTGAAATATGGATGCTTTTTG-3' \\
PER2-shRNA-III & 5'-CCGGGCACACACACAAAGAACTGATACTCGAGTATCAGTTCTTTGTGTGTGTCTTTTTG-3'
\end{tabular}

PER2, period circadian clock 2; shRNA, short hairpin RNA.

A

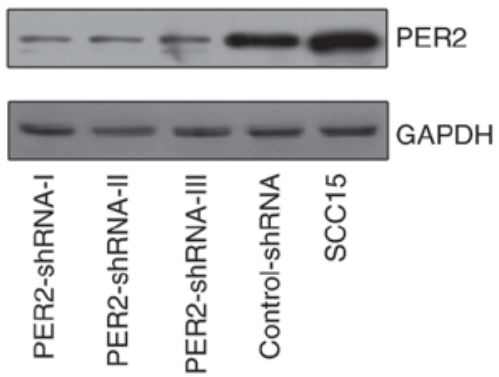

B

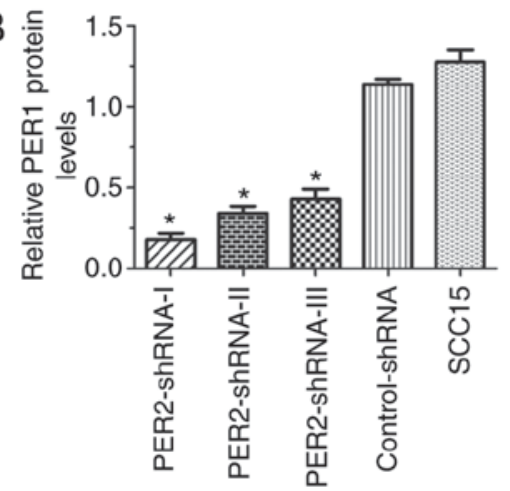

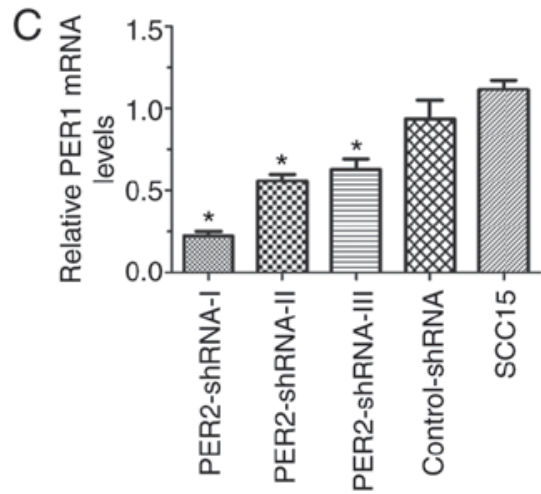

Figure 1. PER2 is most significantly knocked down in the PER2-shRNA-I group among the five groups of SCC15 cells. (A) Protein expression of PER2 in the PER2-shRNA-I-III, control-shRNA and SCC15 groups. (B) Protein expression of PER2 was significantly reduced in PER2-shRNA-I-III groups compared with in the control-shRNA and SCC15 groups. (C) mRNA expression of PER2 was significantly reduced in the PER2-shRNA-I-III groups compared with in the control-shRNA and SCC15 groups, and this difference was largest for the PER-shRNA-1 group. Data are presented as the mean \pm standard deviation. ${ }^{*} \mathrm{P}<0.05$. PER2, period circadian clock 2; shRNA, short hairpin RNA.

deviation. $\mathrm{P}<0.05$ was considered to indicate a statistically significant difference.

\section{Results}

Construction and sequencing of shRNA lentiviral plasmids. The sequencing results obtained from the lentiviral plasmids, PER2-shRNA-I-III, are presented in Table III. These sequences exactly matched the interference target sequences of the positive-sense strands of PER2-shRNA-I-III, indicating that three interference target sequences of PER2 were successfully constructed.

mRNA and protein expression of PER2 in SCC15 cells following transfection. The mRNA and protein expression of PER2 in the PER2-shRNA-I-III, control-shRNA and untransfected SCC15 groups are presented in Fig. 1. The PER2 mRNA and protein expression in the PER2-shRNA-I group was significantly lower than in the other groups $(\mathrm{P}<0.05)$, indicating that the PER2 knockdown was most effective in the PER2-shRNA-I group. Therefore, this shRNA was selected for use in the subsequent experiments.

mRNA expression of clock genes in SCC15 cells following PER 2 knockdown. RT-qPCR analysis demonstrated that the mRNA expression levels of PERI and REV-ERB $\alpha$ were significantly upregulated in the PER2-shRNA-I group compared with in the control-shRNA and SCC15 groups $(\mathrm{P}<0.05)$, while the mRNA expression levels of PER3, BMAL1, DEC1,DEC2,
CRY2, TIM, ROR $\alpha$ and NPAS2 were significantly downregulated $(\mathrm{P}<0.05)$. There was no significant difference between mRNA expression levels in the control-shRNA and the SCC15 groups $(\mathrm{P}>0.05)$. In addition, there was no significant difference in the mRNA expression levels of CLOCK, CRY1 or $C K I \varepsilon$ among the three groups ( $\mathrm{P}>0.05$; Fig. 2).

Proliferation and apoptosis of SCC15 cells following PER2 knockdown. Flow cytometric analysis indicated that the cell PIs of the PER2-shRNA-I group, control-shRNA group and untreated SCC15 group were 43.55 $\pm 2.64,35.32 \pm 2.64$ and $35.36 \pm 2.46 \%$, respectively. The cell AIs were 15.94 \pm 1.36 , $21.85 \pm 1.90$ and $22.13 \pm 2.29 \%$, respectively. The cell PI of the PER2-shRNA-I group was markedly higher than that of the other two groups, while the cell AI was significantly lower than that of the other two groups $(\mathrm{P}<0.05)$. There was no significant difference between the control-shRNA group and the SCC15 group with regards to PI or AI ( $\mathrm{P}>0.05$; Fig. 3).

\section{Discussion}

Previous studies have indicated that different clock genes regulate various downstream CCGs, and therefore clock genes are considered to be important for regulating cell biochemical and physiological functions (12). The clock gene, $P E R 2$, is downregulated in various types of cancer, and is associated with cancer occurrence and progression via the regulation of numerous downstream cell cycle genes (15-18). Although PER2 is known to be an important 


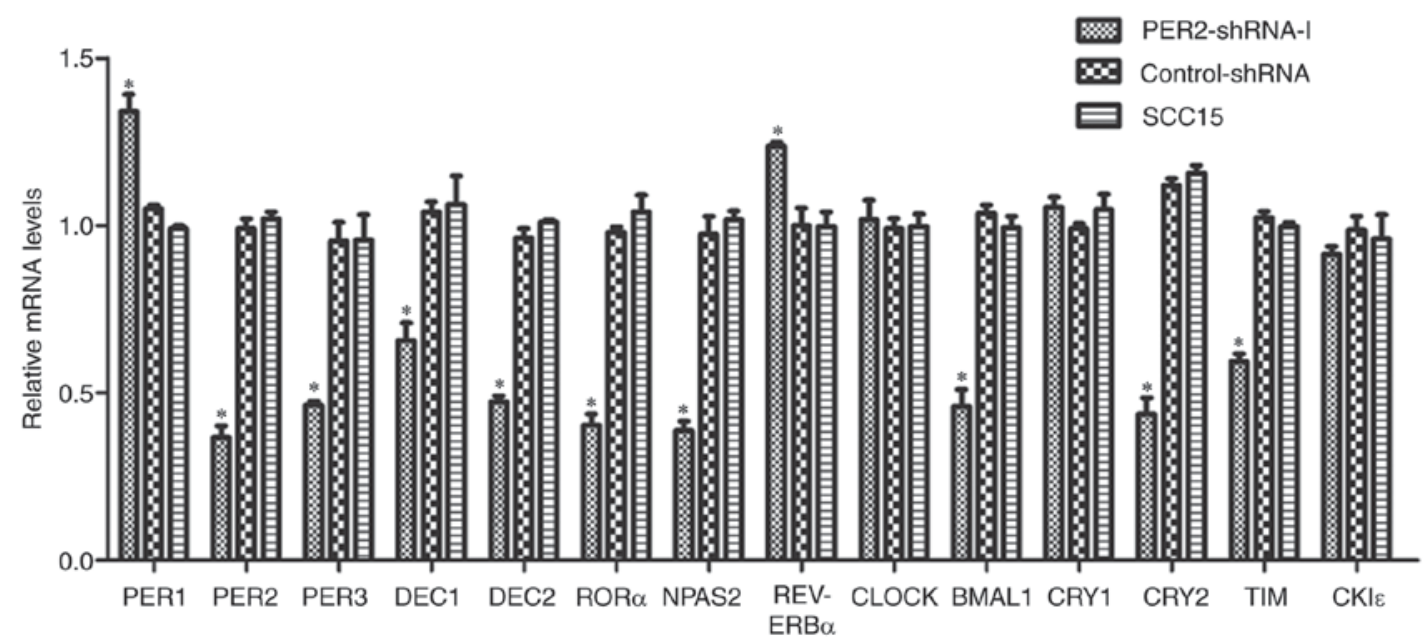

Figure 2. Alteration of mRNA expression of clock genes in SCC15 cells following PER2 knockdown. mRNA expression levels of PER1 and REV-ERB $\alpha$ were significantly upregulated in the PER2-shRNA-I group when compared with in the control-shRNA and SCC15 groups, while the mRNA expression of PER3, BMAL1, DEC1, DEC2, CRY2, TIM, ROR a and NPAS2 was significantly downregulated. There was no notable difference between the control-shRNA and SCC15 groups. The mRNA expression levels of CLOCK, CRY1 and CKIE were not significantly different among the three groups. Data are presented as the mean \pm standard deviation. "P $<0.05$. PER, period circadian clock; $R E V-E R B \alpha$, nuclear receptor subfamily 1 group D member 1 ; shRNA, short hairpin RNA; $B M A L 1$, brain and muscle ARNT-like 1; DEC, deleted in esophageal cancer; $C R Y$, cryptochrome circadian clock; TIM, timeless circadian clock; ROR $\alpha$, retinoic acid receptor-related orphan receptor- $\alpha$; NPAS2, neuronal PAS domain protein 2; CLOCK, clock circadian regulator; $C K I \varepsilon$, casein kinase 1 epsilon.
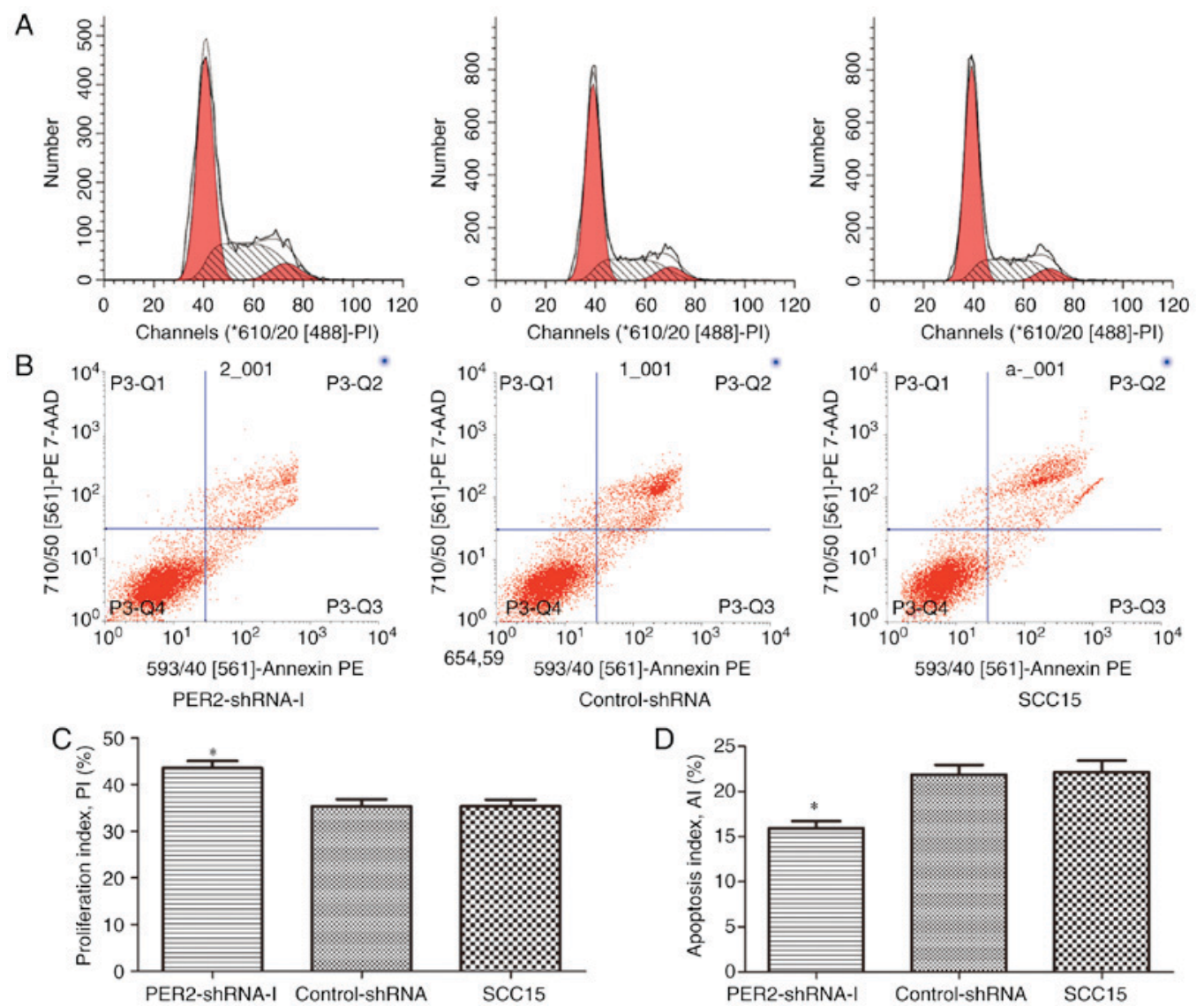

Figure 3. PER2 knockdown enhances proliferation and reduces apoptosis of SCC15 cells. (A) Flow cytometry results of the proliferation of cells in the SCC15, control-shRNA and PER2-shRNA-I groups. (B) Flow cytometry results of the apoptosis of cells in the SCC15, control-shRNA and PER2-shRNA-I groups. (C) The proliferation index was significantly increased in the PER2-shRNA-I group. (D) The apoptosis index was significantly reduced in the PER2-shRNA-I group. Data are presented as the mean \pm standard deviation. " $\mathrm{P}<0.05$. PER, period circadian clock; shRNA, short hairpin RNA.

clock gene (23), whether its reduced expression in cancer may lead to the alteration of other clock genes remains unclear at present.
Research has demonstrated that there is a network structure, including three feedback loops, between clock genes at the translation-transcription levels in normal cells $(4,24-26)$. 
To begin with, BMAL1 combines with CLOCK or NPAS2 to form heterodimers, and acts as a transcription factor to activate the expression of PER genes (PER1, PER2 and $P E R 3), C R Y$ genes (CRY1 and CRY2), DEC genes (DEC1 and $D E C 2), T I M, R O R \alpha$ and $R E V-E R B \alpha$. PER and CRY proteins then combine to form heterodimers and translocate into the cell nucleus to repress the activity of CLOCK/BMAL1 or NPAS2/BMAL1, thereby generating the first negative feedback loop, which is the primary feedback loop in the network $(24,25)$. In the same way, DEC1 and DEC2 proteins form dimers or heterodimers and translocate to the nucleus to inhibit the activity of CLOCK/BMAL1, thereby comprising the second negative feedback loop (26). REV-ERB $\alpha$ and ROR $\alpha$ proteins translocate to the nucleus to suppress and promote the expression of $B M A L 1$, respectively, thereby generating the third feedback loop (4). In normal feedback loops involving the aforementioned clock genes, PER2 is a component of the first, main negative feedback loop, serving as a negative regulatory factor. When the mRNA expression of PER2 is downregulated, its inhibitory effect on the positive-regulatory factors, CLOCK/BMAL1 and NPAS2/BMAL1, is reduced; therefore, PER2 downregulation may lead to higher mRNA expression levels of negative regulatory genes, including $P E R 1, P E R 3, C R Y 1, C R Y 2$, $D E C 1, D E C 2, T I M, R E V-E R B \alpha$ and $R O R \alpha$. However, in the present study, following PER 2 knockdown, the mRNA expression levels of NPAS2 and BMAL1 were significantly downregulated, suggesting that the transcription-activating effect of the positive regulatory factor, CLOCK/BMAL1, is suppressed. Among the negative regulatory genes, only the mRNA expression levels of PERI and REV-ERB $\alpha$ were significantly upregulated, which is consistent with the features of circadian feedback regulation in normal cells. By contrast, the mRNA expression of remaining negative regulatory genes, including $P E R 3, D E C 1, D E C 2, C R Y 2, T I M$ and $R O R \alpha$, was downregulated, and the mRNA expression of $C R Y 1$ was not significantly altered, which was not consistent with the features of circadian feedback regulation in normal cells. We hypothesized that the reason for this difference may be that the three known feedback loops have been researched in normal cells $(4,24-26)$, while the present study was conducted using cancer cells. Therefore, the regulatory effects of circadian positive- and negative-feedback networks in cancer cells may have been altered, or there may exist other compensatory regulatory approaches. However, this requires further investigation.

In the present study, the mRNA expression levels of the $C L O C K$ gene were not notably altered following PER 2 knockdown in human OSCC cells. A previous study by Lee et al (27), conducted in normal mouse liver cells, demonstrated that $C L O C K$ was not changed by the alteration of PER 2 mRNA expression. Additionally, Shearman et al (3) reported that, in normal mouse liver cells, PER2 knockdown did not alter the expression of CLOCK protein, but instead promoted the nuclear translocation of the CLOCK/BMAL1 heterodimer to act as a transcription factor. Therefore, we hypothesized that the regulatory effect of silencing $P E R 2$ on the positive regulatory factor $C L O C K$ may result from changes in its intracellular distribution. In addition, $P E R 2$ may exert no regulation on $C L O C K$ at the transcriptional level.
In summary, the clock gene, $P E R 2$, has previously been reported to be downregulated in various types of cancer, and to be involved in the occurrence and progression of cancer via the regulation of downstream cell cycle genes $(18,19)$. The present study has demonstrated that PER2 is also important in the regulation of the clock gene network, which contributes to the previously established knowledge regarding PER2 function. To the best of our knowledge, the present study is the first to report that the reduced expression of PER2 significantly decreases the mRNA expression levels of PER3, BMAL1, DEC1, DEC2, CRY2, TIM, ROR $\alpha$ and NPAS2 in cancer cells, while the mRNA expressions of PERI and REV-ERB $\alpha$ were significantly upregulated. These observations also indicated that that PER2 knockdown enhances the proliferation and reduces the apoptosis of OSCC cells. In conclusion, PER2 serves an important role in regulating other clock genes in the clock gene network in cancer cells. This is of great importance in further illustrating the molecular functions and tumor-suppressor mechanisms of PER2. However, the results of the present study identified the effects on expression at the transcriptional level, and further studies at the translational level are required in the future.

\section{Acknowledgements}

The authors would like to thank Master of Medicine (MM) Xiao-Juan Fu and Han-Xue Li of The First Affiliated Hospital of Chongqing Medical University for providing technical and statistical assistance. The authors would also like to thank Dr Qing-Qing Wang of Stomatological Hospital of Chongqing Medical University, for aiding in the conduction of certain experiments.

\section{References}

1. Fu L and Lee CC: The circadian clock: Pacemaker and tumour suppressor. Nature Rev Cancer 3: 350-361, 2003.

2. Ye H, Yang K, Tan XM, Fu XJ and Li HX: Daily rhythm variations of the clock gene PER 1 and cancer-related genes during various stages of carcinogenesis in a golden hamster model of buccal mucosa carcinoma. Onco Targets Ther 8: 1419-1426, 2015.

3. Shearman LP, Sriram S, Weaver DR, Maywood ES, Chaves I, Zheng B, Kume K, Lee CC, van der Horst GT, Hastings MH and Reppert SM: Interacting molecular loops in the mammalian circadian clock. Science 288: 1013-1019, 2000.

4. Preitner N, Damiola F, Lopez-Molina L, Zakany J, Duboule D, Albrecht $U$ and Schibler U: The orphan nuclear receptor REV-ERBalpha controls circadian transcription within the positive limb of the mammalian circadian oscillator. Cell 110: 251-260, 2002.

5. Zhao N, Yang K, Yang G, Chen D, Tang H, Zhao D and Zhao C: Aberrant expression of clock gene period1 and its correlations with the growth, proliferation and metastasis of buccal squamous cell carcinoma. PLoS One 8: e55894, 2013.

6. Lowrey PL and Takahashi JS: Genetics of the mammalian circadian system: Photic entrainment, circadian pacemaker mechanisms, and posttranslational regulation. Annu Rev Genet 34: 533-562, 2000.

7. Rana S and Mahmood S: Circadian rhythm and its role in malignancy. J Circadian Rhythms 8: 3, 2010.

8. Bozek K, Relogio A, Kielbasa SM, Heine M, Dame C, Kramer A and Herzel H: Regulation of clock-controlled genes in mammals. PLoS One 4: e4882, 2009.

9. Chu G, Yoshida K, Narahara S, Uchikawa M, Kawamura M, Yamauchi N, Xi Y, Shigeyoshi Y, Hashimoto S and Hattori MA: Alterations of circadian clockworks during differentiation and apoptosis of rat ovarian cells. Chronobiol Int 28: 477-487, 2011. 
10. Filipski E, King VM, Li X, Granda TG, Mormont MC, Liu X, Claustrat B, Hastings MH and Lévi F: Host circadian clock as a control point in tumor progression. J Natl Cancer Inst 94: 690-697, 2002.

11. Hayashida S, Kuramoto Y, Koyanagi S, Oishi K, Fujiki J, Matsunaga N, Ikeda E, Ohdo S, Shimeno H and Soeda S: Proxisome proliferator-activated receptor- $\alpha$ mediates high-fat, diet-enhanced daily oscillation of plasminogen activator inhibitor-1 activity in mice. Chronobiol Int 27: 1735-1753, 2010.

12. Panda S, Antoch MP, Miller BH, Su AI, Schook AB, Straume M, Schultz PG, Kay SA, Takahashi JS and Hogenesch JB: Coordinated transcription of key pathways in the mouse by the circadian clock. Cell 109: 307-320, 2002.

13. Miyazaki K, Wakabayashi M, Hara Y and Ishida N: Tumor growth suppression in vivo by overexpression of the circadian component, PER2. Genes Cells 15: 351-358, 2010.

14. Yang X, Wood PA, Ansell C and Hrushesky WJ: Circadian time-dependent tumor suppressor function of period genes. Integr Cancer Ther 8: 309-316, 2009.

15. Chen ST, Choo KB, Hou MF, Yeh KT, Kuo SJ and Chang JG: Deregulated expression of the PER1, PER2 and PER3 genes in breast cancers. Carcinogenesis 26: 1241-1246, 2005.

16. Zhao H, Zeng ZL, Yang J, Jin Y, Qiu MZ, Hu XY, Han J, Liu KY, Liao JW, Xu RH and Zou QF: Prognostic relevance of Period1 (Per1) and Period2 (Per2) expression in human gastric cancer. Int J Clin Exp Pathol 7: 619-630, 2014.

17. Hsu CM, Lin SF, Lu CT, Lin PM and Yang MY: Altered expression of circadian clock genes in head and neck squamous cell carcinoma. Tumour Biol 33: 149-155, 2012.

18. Wang Q, Ao Y, Yang K, Tang H and Chen D: Circadian clock gene Per2 plays an important role in cell proliferation, apoptosis and cell cycle progression in human oral squamous cell carcinoma. Oncol Rep 35: 3387-3394, 2016.

19. Tan XM, Ye H, Yang K, Chen D, Wang QQ, Tang H and Zhao NB: Circadian variations of clock gene Per2 and cell cycle genes in different stages of carcinogenesis in golden hamster buccal mucosa. Sci Rep 5: 9997, 2015.
20. O'Driscoll A, Belogrudov V, Carroll J, Kropp K, Walsh P Ghazal P and Sleator RD: HBLAST: Parallelised sequence similarity-A Hadoop MapReducable basic local alignment search tool. J Biomed Inform 54: 58-64, 2015.

21. Chernolovskaya EL and Zenkova MA: Design of nucleaseresistant fork-like small interfering RNA (fsiRNA). Methods Mol Biol 942: 153-168, 2013.

22. Livak KJ and Schmittgen TD: Analysis of relative gene expression data using real-time quantitative PCR and the 2(-Delta Delta C(T)) method. Methods 25: 402-408. 2001.

23. Militi S, Maywood ES, Sandate CR, Chesham JE, Barnard AR, Parsons MJ, Vibert JL, Joynson GM, Partch CL, Hastings MH and Nolan PM: Early doors (Edo) mutant mouse reveals the importance of period 2 (PER2) PAS domain structure for circadian pacemaking. Proc Natl Acad Sci USA 113: 2756-2761, 2016.

24. Gekakis N, Staknis D, Nguyen HB, Davis FC, Wilsbacher LD, King DP, Takahashi JS and Weitz CJ: Role of the CLOCK protein in the mammalian circadian mechanism. Science 280: 1564-1569, 1998

25. Borgs L, Beukelaers P, Vandenbosch R, Belachew S, Nguyen L and Malgrange B: Cell 'circadian' cycle: New role for mammalian core clock genes. Cell Cycle 8: 832-837, 2009.

26. Nakashima A, Kawamoto T, Honda KK, Ueshima T, Noshiro M, Iwata T, Fujimoto K, Kubo H, Honma S, Yorioka N, et al: DEC1 modulates the circadian phase of clock gene expression. Mol Cell Biol 28: 4080-4092, 2008.

27. Lee C, Etchegaray JP, Cagampang FR, Loudon AS and Reppert SM: Posttranslational mechanisms regulate the mammalian circadian clock. Cell 107: 855-867, 2001.

cc) () $\odot$ This work is licensed under a Creative Commons cc) Attribution-NonCommercial-NoDerivatives 4.0 International (CC BY-NC-ND 4.0) License. 